\title{
Acoustic restoration: using soundscapes to benchmark and fast-track rehabilitation of ecological communities
}

\author{
Elizabeth Znidersic ${ }^{1}$ and David Watson ${ }^{1}$ \\ ${ }^{1}$ Charles Sturt University
}

November 25, 2021

\begin{abstract}
We introduce a new approach-acoustic restoration-focusing on the applied utility of soundscapes for restoration, recognizing the rich ecological and social values they encapsulate. Broadcasting soundscapes in disturbed areas can accelerate recolonization of animals and the microbes and propagules they carry; long duration recordings are also ideal sources of data for benchmarking restoration initiatives and evocative engagement tools.
\end{abstract}

Acoustic restoration: using soundscapes to benchmark and fast-track rehabilitation of ecological communities Elizabeth Znidersic** and David M Watson

Address and affiliations: School of Agricultural, Environmental and Veterinary Sciences Charles Sturt University

Albury NSW 2640 Australia

*Corresponding author : eznidersic@csu.edu.au

Word count: 1,998 words (excluding 59 word abstract, 50 references, one table and one figure)

Submitted: 18 November 2021, to be considered for publication in Ecology Letters as a Viewpoint (initial proposal approved by senior editor Peter Thrall, 29 September 2021)

Keywords: Ecoacoustics, social attraction, microbial ecology, engagement, disturbance

Abstract: We introduce a new approach-acoustic restoration-focusing on the applied utility of soundscapes for restoration, recognizing the rich ecological and social values they encapsulate. Broadcasting soundscapes in disturbed areas can accelerate recolonization of animals and the microbes and propagules they carry; long duration recordings are also ideal sources of data for benchmarking restoration initiatives and evocative engagement tools.

Authorship statement: EZ responsible for the original concept of acoustic restoration, wrote the sections on acoustic lures and soundscape ecology. DMW responsible for the idea of microbial augmentation and aquatic applications, wrote majority of the first draft. EZ and DMW equally responsible for concept of acoustic benchmarking, both authors contributed to revisions.

Data accessibility statement: No new data are presented in this manuscript, the long duration acoustic data summarized in Fig. 1 are derived from the open access Australian Acoustic Observatory, https://acousticobservatory.org

As catastrophic wildfires, heatwaves and storms increase in frequency and severity, both terrestrial and aquatic ecosystems face mounting pressures, pushing relictual populations towards local extinction and 
compromising ecosystem function. Current restoration praxis was originally developed as site-scale secondary interventions-removing primary stressors and relying on natural regeneration to do the rest. While this passive approach has made way for active interventions (Table 1), most are too effort-intensive to apply beyond the individual site scale. Out-of-the-box thinking is urgently needed to develop scalable and rapidly deployable methods to arrest further declines, complimenting existing interventions to facilitate recovery.

After a sustained period of innovation and growth, a critical mass of acoustic ecology research and practice has been reached, evidenced by large-scale government investment in infrastructure (Roe et al.2021), international data-sharing networks and adoption of standard operating procedures to maximise comparability (Browning et al.2017). An idea that emerged from our use of sound to survey both species and communities over the past decade is to reimagine this monitoring tool as an active restoration approach. We name this new field "acoustic restoration", emphasising soundscapes as holistic high resolution digital depictions of their respective landscapes (Schafer 1977) and recognizing the biological, geophysical and socio-cultural values they encapsulate (Pijanowski et al. 2011; Parker \& Spennemann 2021).

Here we introduce the idea and develop four elements of this novel transdisciplinary domain. The first broadens existing use of acoustic lures to attract single species up to entire assemblages, broadcasting soundscapes to fast-track recolonization of communities from the top down. The second element uses increased animal visitation to augment the rain of seeds, spores, bacteria and fungi to re-inoculate aquatic and terrestrial communities, rehabilitating ecosystems from the bottom up. Third, we suggest sound represents an ideal benchmark for restoration, providing an independent and verifiable means of answering the question-are we there yet? Finally, we advocate using soundscapes as evocative engagement tools to remind stakeholders what their river, reef or rainforest sounded like and create new ways to reconnect with places they hold dear.

Acoustic lures are an existing tool in the restorationist's repertoire, used for various vocal animal groups to elicit a response for detection, capture or attract individuals to specific locations and encourage breeding. To accelerate establishment or recolonisation through social attraction, species-specific acoustic lures have been applied successfully to frogs (James et al. 2015), seabirds (Arnoldet al. 2011; Herrera-Giraldo et al. 2021), bats (Ruffellet al. 2009), coral reef fish (Gordon et al. 2019) and whales (Tyack et al. 2011), proving especially effective for long-lived colonial animals that remember using that location prior to disturbance (Jones \& Kress 2012). Putman and Blumstein (2019) flagged the potential for using call playback to recruit animals into newly restored habitats but expanding this approach up to community-scale interventions has not been considered. As well as animal vocalizations, sounds emanate from other biological, anthropogenic and geophysical sources which can act as individual or collective cues for species (Pijanowski 2011). In addition to indicating where to go (e.g.,settlement response to reef sounds by crab and oyster larvae; Stanleyet al. 2009, Lillis et al. 2013), not go (e.g.,avoidance of anthropogenic sounds by cetaceans and fruit bats; Tyacket al. 2011, Ruffell et al. 2009), or how to get there (e.g., encouraging frogs to cross railways via wildlife underpasses; Testud et al. 2020), sounds can alter behaviours (e.g., rainfall sounds trigger breeding behaviour in frogs; Muñozet al. 2020).

The same technology used to make passive acoustic sensors for collecting long-duration recordings can readily be repurposed to make autonomous playback devices, matching the soundtrack to the location and substrate, and optimising the duty cycle to the target species and acoustic theatre (e.g., nocturnal playback of flight calls for passage migrant birds, broadcasting frog choruses after significant rainfall). By playing segments of an entire soundscape or curated compilations of key vocal species ('mix tapes'), concerns over temporary habituation can be minimized noting that, despite oft-shared anecdotes, direct evidence of deleterious impacts of call playback is scant (Watson et al.2018). Comparing mix tapes with natural or edited soundscapes, mechanistic cues used by various animal groups can be identified, allowing progressively more tailored lures for particular restoration or remediation contexts. Pairing the use of lures with sensor-based surveys (passive acoustic recorders, camera traps, even web-cams), large-scale restoration initiatives can be conducted and monitored in remote and inhospitable landscapes, control sites restored using conventional practices providing time-matched counterfactuals to quantify any initial or medium-term differences. In addition to minimizing demographic and genetic losses from initial disturbance, fast-tracking recolonization can prevent 
encroachment of despotic species that aggressively exclude subsequent colonists from the original assemblage (Leseberg et al. 2015).

Regardless of whether visiting animals decide to stay, simply attracting passing animals to target sites will augment recolonization of the bacteria, fungi, protists and plankton that perform foundational roles in food webs. Mycorrhizal fungi can take decades to return after catastrophic wildfire (Dove \& Hart 2017), while the microbial films that underly energy flux in freshwater systems can take over a century to recover from industrial pollution (Vrba et al. 2003). The simplified microbial communities that characterize disturbed systems diminish their resilience, increasing sensitivity to additional disturbance events. The idea of using visiting animals to fast-track restoration has been trialled before, primarily in reforesting agricultural land where the addition of artificial perches to cleared areas facilitates dispersal of large-seeded plants by visiting birds (Wunderle 1997, Athiê and Dias 2016). Although more relevant in terrestrial systems, the potential for wide-ranging aquatic organisms to seed microbial recovery has been noted by researchers working on both marine reefs (e.g., fish accelerating recovery of coral endosymbionts after bleaching events; Grupsta et al. 2021) and freshwater wetlands (e.g., the microbiome of fish homogenizing river bacterial communities; Zha et al. 2020). In addition to fungi and bacteria, seeds and small animals are transported by birds (Fontenato 2019, González-Varo et al. 2019) and fish (Schofield et al. 2018, Goulding et al. 1990) effecting long-distance dispersal across inhospitable intervening areas.

A frequently recognized failing of restoration initiatives is brokering agreement on the answer to the question: 'What does success look like?' (after Prach et al. 2019). Acoustic restoration recasts this question as "What does success sound like?". For mining and other commercial infrastructure development, pre-disturbance recordings from impacted sites offer a quantifiable benchmark for future restoration practitioners to work towards. For already disturbed sites, soundscapes from adjacent areas or ecologically similar reference sites can provide high resolution data about both species assemblages and structural characteristics that can be logistically complex to estimate at the whole-of-system scale. Current ecoacoustics allows a suite of metrics to be extracted from recordings (Fig. 1), including species richness (Towsey et al. 2013) and identification of dominant taxa, but also seasonal dynamics, breeding events, even estimating canopy complexity by quantifying how sound from storms dissipates (Haskell 2020). Progressive monitoring of restored sites will reveal which targets are met and which are yet to be attained, prioritising on-ground actions to optimise recovery. Noting recent advances in estimating abundances, identifying individuals, detecting reproductive events, mass flowering and even predation success with current analysis and visualisation techniques (Browning et al. 2017 and references therein), burgeoning ecoacoustics research will enable future practitioners to extract progressively more historic information from archived recordings, giving restoration practitioners a trove of pre-disturbance metrics to gauge the functional success of their work.

Finally acoustic restoration offers unparalleled opportunities for deep, meaningful engagement. Sounds are evocative and every place has its own soundscape (Schafer 1977, Pijanowski 2011). Farmers remember curlews calling on moonlit nights when they were children (Robb et al.2012), chorusing cicadas alert rainforest people to heat waves in the treetops (Feld et al. 2020). The sounds of animals and particular winds or waves feature strongly in First Nation accounts of places of cultural significance (Parker \& Spennemann 2021). In addition to rallying communities to restore connections with what places once sounded like, natural sounds have a range of health benefits (Buxtonet al. 2021), tangible reminders of the value of immersive outdoor experiences. Natural sounds transcend human language, online and mobile platforms defining new ways for the environment to project its own voice into the boardrooms, studios and chambers where critical decisions are made. More soberingly, as development escalates and entire biomes make way for production agriculture and aquaculture, archived soundscape recordings and the whole-of-assemblage permanent records they represent will remind people what wild places were once like.

Acoustic ecology has surged in popularity as a compliment to existing ecological techniques, due primarily to the rich resolution and archival stability of acoustic data. As the 'hype' recedes and our transdisciplinary field matures, we see great benefits of applying acoustic ecology to the practice of ecological restoration. As well as cost-effective and nimble (deployable within hours of disturbance events), acoustic restoration 
minimises the need for ongoing visits by teams of people, reducing risks of site disturbance and inadvertent introduction of invasive species and pathogens. In addition to wildfire, coral bleaching, blackwater events and catastrophic storms, acoustic restoration could be used proactively to push range shifts toward unoccupied but otherwise suitable future habitats to minimize climate impacts, for both resident and migratory assemblages in insular and extensive systems. Advances in eDNA sequencing and semi-automated identification using DNA-barcoding entrain reliable means of quantifying change in microbial communities-both occurrence and genetic interchange-with parallel work on seedling emergence, soil and water properties enabling quantification of changes to plant populations and ecosystem health. Rather than chasing shifting baselines or arguing about the unreliability of indicator taxa or space-for-time substitutions, archived open access soundscapes can guide diverse stakeholder groups towards a common purpose, defining on-ground work towards agreed targets representing the true complexity of ecosystems.

To realise these benefits and maximise the utility of acoustic restoration, we suggest four priority actions. First, we urge empirical ecologists to collect long duration recordings as part of their fieldwork. With equipment now readily available, recording soundscapes and associated metadata should be as routine as taking photographs of your study area. As large distributed arrays of acoustic sensors are being established to track environmental change at continental scales (Roe et al. 2021), investment will be increasingly directed towards platforms to store, share and visualise these data. Second, we encourage researchers and practitioners alike to listen to their systems. The simple observation that "higher quality woodlands rustle underfoot" (Freudenberger, in litt .) presaged the importance of productivity, litterfall and litter-dwelling invertebrates in driving woodland food-webs (Watson 2011). The very act of recording sounds increases one's awareness of the surrounding landscape (Feld et al. 2020) and helps tune one's understanding of the underlying variability and constitutive complexity. Third, think beyond species. While species recognition is increasingly achievable for many animal groups, using ecoacoustics to quantify species richness is akin to using satellite photography to identify vegetation types. It's not the best tool for the job. False colour spectrograms and other applications of acoustic indices are readily able to extract a variety of metrics from recordings, many of which are likely influenced by the same suite of underlying mechanisms that determine species occurrence and community composition. Looking past species to these biotic and abiotic gradients will reveal new variables that ecoacoustics is far better suited to quantify - the underlying topography sculpting productivity, seasonality, resilience and energy flux. Finally, collaborate; with acoustics specialists that can test microphones, calibrate equipment and ensure metadata are associated and complete; with environmental DNA specialists that can take a vial of water or bag of soil and tell you how many species of salamander live in that forest; with microbial ecologists that can take those samples and quantify how many taxa have recovered in that site since the last samples were taken. Restoring our streams and grasslands, our mangroves and estuaries, wetlands and saltmarshes is a top priority, remediating past damage and responding rapidly to future disturbance. Grounded in collaboration and facilitated by digital technology, acoustic restoration compliments existing on-ground approaches using the unique properties of sound to accelerate, augment, benchmark and engage.

\section{References}

Arnold, J.M., Nisbet, I.C.T. \& Veit, R. (2011). Assessing aural and visual cueing as tools for seabird management. J Wildl Mgmt 75, 495-500.

Athiê, S. \& Dias, M. (2016). Use of perches and seed dispersal by birds in an abandoned pasture in the Porto Ferreira state park, southeastern Brazil. Braz J Biol 76, 80-92.

Brown S.L., Reid, N., Reid, J., Smith, R., Whalley, R.D.B. \& Carr D. (2017). Topsoil removal and carbon addition for weed control and native grass recruitment in a temperate derived grassland in northern New South Wales. Rangeland J 39, 355-361.

Browning, E., Gibb, R., Glover-Kapfer, P. \& Jones, K.E. (2017). Passive acoustic monitoring in ecology and conservation. Woking, UK, WWF-UK, 76pp. (WWF Conservation Technology Series 1(2)).

Buxton, R.T., Pearson, A.L., Allou, C., Fristrup, K. \& Wittemyer, G. (2021). A synthesis of health benefits of natural sounds and their distribution in national parks. Proc Nat Acad Sci 118, e2013097118. 
Cowan, M.A., Callan, M.N., Watson, M.J., Watson, D.M., Doherty, T.S., Michael, D.R. et al . (2021). Artificial refuges for wildlife conservation: what is the state of the science? Biol Rev 96, 2735-2754.

Dove, N.C. \& Hart, S.C. (2017). Fire reduces fungal species richness and in situ mycorrhizal colonization: a meta-analysis. Fire Ecol 13, 37-65.

Ellison, A.M., 2000. Mangrove restoration: do we know enough?Restor Ecol 8, 219-229.

Erskine, W.D. \& Webb, A.A. (2003). Desnagging to resnagging: new directions in river rehabilitation in southeastern Australia.River Res Appl 19, 233-249.

Feld, S., Barker, M. \& Nakassis, C. (2020). Spectral signage: a discussion with Steven Feld. Semiotic Review 9 .

Fontaneto, D. (2019). Long-distance passive dispersal in microscopic aquatic animals. Mov Ecol 7, 10.

Glen, A.S., Atkinson, R., Campbell, K.J., Hagen, E., Holmes, N.D., Keitt, B.S. et al. (2013). Eradicating multiple invasive species on inhabited islands: the next big step in island restoration?Biol Invasions 15, 2589-2603.

González-Varo, J.P., Díaz-García, S, Arroyo, J.M. \& Jordano, P. (2019). Seed dispersal by dispersing juvenile animals: a source of functional connectivity in fragmented landscapes. Biol Lett 15, 2019026420190264.

Gordon, T.A.C., Radford, A.N., Davidson, I.K., Barnes, K., McCloskey, K., Nedelec, S.L. et al. (2019). Acoustic enrichment can enhance fish community development on degraded coral reef habitat. Nat Commun $10,5414$.

Goulding M., Leal Carvajho, M. \& Ferreira, EG. (1990). Rio Negro-Rich Life in Poor Water. SPB Academic Publishing, The Hague.

Greenberg, C.H. \& Collins, B.S. (2015). Natural Disturbances and Historic Range of Variation: Type, Frequency, Severity, and Post-disturbance Structure in Central Hardwood Forests USA . Heidelberg, Germany: Springer.

Grupstra, C.G.B., Rabbitt, K.M., Howe-Kerr, L.I. \& Correa, A.M.S. (2021). Fish predation on corals promotes the dispersal of coral symbionts. Anim Microbiome 3, 25.

Haskell, D. (2020). The Songs of Trees: Stories from Nature's Great Connectors . Black Inc. 304 pp.

Herrera-Giraldo, L., Figuerola, C.E., Wolf, C.A., Colon-Merced, R., Ventosa-Febles, E., Silander, S. \& Holmes, N.D. (2021). The use of social attraction techniques to restore seabird colonies on Desecheo Island, Puerto Rico. Ecol Solut Evid 2, e12058.

Jaap, W.C. (2000). Coral reef restoration. Ecol Eng 15, 345-364.

James, M.S., Stockwell, M.P., Clulow, J., Clulow, S. \& Mahony, M.J. (2015). Investigating behaviour for conservation goals: conspecific call playback can be used to alter amphibian distributions within ponds.Biol. Cons. 192:287-293.

Jones, H.P. \& Kress, S.W. (2012). A review of the world's active seabird restoration projects. J Wildl Mgmt $76,2-9$.

Leseberg, N.P., Lambert, K.T.A. \& McDonald, P.G. (2015). Fine-scale impacts on avian biodiversity due to a despotic species, the bell miner (Manorina melanophrys ). Austral Ecol 40, 245-254.

Lillis, A., Eggleston, D. \& Bohnenstiehl, D.R. (2013). Oyster larvae settle in response to habitat-associated underwater sounds. PloS One 8, e79337.

Linhart, Y.B. (1995). Restoration, revegetation, and the importance of genetic and evolutionary perspectives. p. 271-287. In B.A. Roundyet al. (ed.) Proc Wildland Shrub and Arid Land Restoration Symp , Las Vegas, NV. 19-21 Oct. 1993. Gen. Tech. Rep. INT-GTR-315. U.S. Forest Service, Ogden, UT. 
Muñoz, M.I., Quispe, M., Maliqueo, M. \& Penna, M. (2020). Biotic and abiotic sounds affect calling activity but not plasma testosterone levels in male frogs (Batrachyla taeniata) in the field and in captivity. Horm Behav 118, 104605.

Parker, M. \& Spenneman, D.H.R. (2021). Classifying sounds: a tool to enrich intangible heritage management. Acoust Austhttps://doi.org/10.1007/s40857-021-00257-y

Pedroli, B., De Blust, G., Van Looy, K. \& Van Rooij, S. (2002). Setting targets in strategies for river restoration. Landscape Ecol 17, 5-18.

Pijanowski, B.C. (2011). What is soundscape ecology? An introduction and overview of an emerging new science. Landscape Ecol 26 1213-1232.

Pijanowski, B.C., Villanueva-Rivera, L.J., Dumyahn, S.L., Farina, A., Krause, B.L., Napoletano, B.M., Gage, S.H. \& Pieretti, N. (2011). Soundscape ecology: the science of sound in the landscape.BioScience 61 203-216.

Prach, K., Durigan, G., Fennessy, S., Overbeck, G.E., Marcelo Torezan, J. \& Murphy, S.D. (2019). A primer on choosing goals and indicators to evaluate ecological restoration success. Restor Ecol 27 917-923.

Putman, B.J. \& Blumstein, D.T. (2019). What is the effectiveness of using conspecific or heterospecific acoustic playbacks for the attraction of animals for wildlife management? A systematic review protocol. Env Evidence 8, 6.

Robb, M., Robb, D., Robb C., Lavis, E., \& Mottram A. (2012).Farmer Alastair and the Bush stone-curlews . Murray Darling Association.

Roe, P., Eichinski, P., Fuller, R.A., McDonald, P.G., Schwarzkopf, L., Towsey, M. et al. (2021). The Australian Acoustic Observatory. Methods in Ecol. \& Evol. 12, 1802-1808.

Ruffell, J., Guilbert, J. \& Parsons, S. (2009). Translocation of bats as a conservation strategy: previous attempts and potential problems. Endang Species Res 8, 25-31.

Schafer, R.M, (1977). The Soundscape. Our Sonic Environment and the Tuning of the World . Destiny Books, Vermont, USA.

Schofield, K.A., Alexander, L.C., Ridley, C.E., Vanderhoof, M.K., Fritz, K. M., Autrey, B.C. et al . (2018). Biota connect aquatic habitats throughout freshwater ecosystem mosaics. JAWRA 54, 372-399.

Seddon, P.J. (2010). From reintroduction to assisted colonization: moving along the conservation translocation spectrum. Restor Ecol18, 796-802.

Stanley, J.A., Radford, C.A. \& Jeffs, A. G. (2009). Induction of settlement in crab megalopae by ambient underwater reef sound.Behav Ecol 21, 113-120.

Testud, G. Fauconnier, C., Labarraque, D., Lengagne, T., Le Petitcorps, Q. et al. (2020). Acoustic enrichment in wildlife passages under railways improves their use by amphibians. Global Ecol 83 Conserv24, e01252.

Towsey, M., Wimmer, J., Williamson, I. \& Roe, P. (2014). The use of acoustic indices to determine avian species richness in audio-recordings of the environment. Ecol Informatics 21, 110-119.

Tyack, P.L., Zimmer, W.M.X., Moretti, D., Southall, B.L., Claridge, D.E., Durban, J.W. et al. (2011). Beaked whales respond to simulated and actual navy sonar. PloS One 6, e1709.

Veitch, C.R. \& Clout, M.N. (2002). Turning the Tide: the Eradication of Invasive Species . Auckland, New Zealand: International Union for Conservation of Nature and Natural Resources.

Vrba, J., Kopáček, J., Fott, J., Kohout, L., Nedbalová, L., Pražáková, M. et al. (2003). Long-term studies (1871-2000) on acidification and recovery of lakes in the Bohemian Forest (central Europe). Sci Total Environ $310,73-85$. 
Watson, D.M. (2011). A productivity-based explanation for woodland bird declines: poorer soils yield less food. Emu, 111:10-18.

Watson, D.M., Znidersic, E. \& Craig, M. (2018). Ethical birding, call playback and conservation. Cons Biol $33,469-471$.

Watson, D.M. \& Watson, M.J. (2015). Wildlife restoration: mainstreaming translocations to keep common species common. Biol Cons 191, 830-838.

Woldendorp, G. \& Keenan, R.J. (2005). Coarse woody debris in Australian forest ecosystems: a review. Aust Ecol 30, 834-843.

Wunderle, J.M., Jr. (1997). The role of animal seed dispersal in accelerating native forest regeneration on degraded tropical lands. For Ecol $\& 3$ Mgmt 99, 223-235.

Zha, Y., Lindström E.S., Eiler A. \& Svanbäck, R. (2020). Different roles of environmental selection, dispersal and drift in the assembly of intestinal microbial communities of freshwater fish with and without a stomach. Front Ecol \& Evol 8, 152.

\section{Captions}

Table 1. The principal techniques presently used for active restoration and remediation after disturbance. Unlike most of these approaches that are best suited to scheduled site-scale initiatives, acoustic restoration is scalable, readily tailored to both aquatic and terrestrial applications and can be rapidly deployed in remote or dangerous landscapes.

Figure 1. Comparison of soundscapes before and after rain at Clump Lagoon, French Island, Australia using long-duration false-colour spectrograms. The $\mathrm{X}$-axis is 24 hours (midnight to midnight), y-axis $0-11,000 \mathrm{~Hz}$ generated by three acoustic indices (ACI acoustic complexity index, ENT spectral entropy and EVN event count index). In addition to quantifying community-wide recovery in wetland-dependent species following drought-breaking rainfall, chorusing insects, songbirds, and individual species can be readily distinguished. This before / after comparison exemplifies the whole-of-system variation encompassed by soundscapes, images that are both high resolution benchmarks informing restoration practitioners and powerful communication tools for the community groups, funding agencies and policy makers investing in on-ground improvements.

Table 1: A restorationist's toolbox

\begin{tabular}{ll}
\hline Approach & Applications and benefits \\
\hline Mechanical and chemical bioremediation & Scalping sites in conjunction with revegetation, chemical dispersers and microbic \\
Replicate historic disturbance regime & Fire and grazing in terrestrial systems, flooding for freshwater systems; range of \\
Revegetation & The default approach for many terrestrial and subtidal biomes, useful way to in \\
Translocation and facilitated dispersal & Routine in freshwater systems, terrestrial applications prioritize ecosystem engin \\
Augmenting natural substrates & Re-snagging and re-meandering rivers, adding coarse woody debris and outcrops \\
Adding engineered structures & Concrete reefs, nest boxes, simulated burrows; all increase heterogeneity of surfa \\
Eradicating invasive species & Reducing populations of invasive species down to a level where displaced native \\
\hline
\end{tabular}

Figure 1. Soundscapes of the same wetland before and after significant rainfall, exemplifying the value of sound to define restoration targets. 


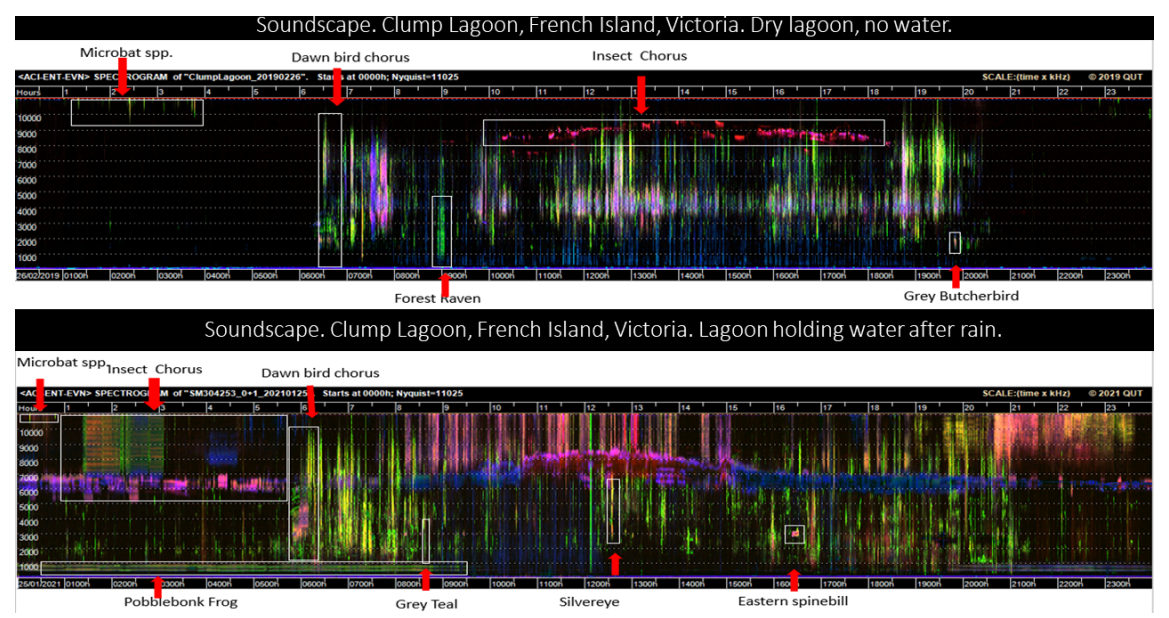

